\title{
An Empirical Non-TNT Approach to Launch Vehicle Explosion Modeling
}

\author{
James M. Blackwood ${ }^{1}$ and Troy Skinner ${ }^{2}$ \\ Bangham Engineering, Jacobs ESSSA Group, Huntsville, AL, 35801, USA \\ Erin H. Richardson ${ }^{3}$ \\ Marshall Space Flight Center, Huntsville, AL, 35811, USA \\ and \\ Michal E. Bangham ${ }^{4}$ \\ Bangham Engineering, Jacobs ESSSA Group, Huntsville, AL, 35801, USA
}

\begin{abstract}
In an effort to increase crew survivability from catastrophic explosions of Launch Vehicles (LV), a study was conducted to determine the best method for predicting $\mathrm{LV}$ explosion environments in the near field. After reviewing such methods as TNT equivalence, Vapor Cloud Explosion (VCE) theory, and Computational Fluid Dynamics (CFD), it was determined that the best approach for this study was to assemble all available empirical data from full scale launch vehicle explosion tests and accidents. Approximately 25 accidents or full-scale tests were found that had some amount of measured blast wave, thermal, or fragment explosion environment characteristics. Blast wave overpressure was found to be much lower in the near field than predicted by most TNT equivalence methods. Additionally, fragments tended to be larger, fewer, and slower than expected if the driving force was from a high explosive type event. In light of these discoveries, a simple model for cryogenic rocket explosions is presented. Predictions from this model encompass all known applicable fullscale launch vehicle explosion data. Finally, a brief description of on-going analysis and testing to further refine the launch vehicle explosion environment is discussed.
\end{abstract}

\section{Nomenclature}

$\begin{array}{ll}\mathrm{AF} & =\text { Air Force } \\ \mathrm{CFD} & =\text { Computational Fluid Dynamics } \\ \mathrm{C}-\mathrm{J} & =\text { Chapman-Jouget } \\ \mathrm{ft} & =\text { feet } \\ \mathrm{HOB} & =\text { Height of Burst } \\ \mathrm{HOVI} & =\text { Hydrogen Oxygen Vertical Impact } \\ \mathrm{K} & =\text { Kelvin } \\ \mathrm{lbs} & =\text { pounds } \\ \mathrm{LH} 2 & =\text { Liquid Hydrogen } \\ \text { LOX } & =\text { Liquid Oxygen } \\ \text { LSHOE } & =\text { Large Scale Hydrogen/Oxygen Explosion } \\ \text { LV } & =\text { Launch Vehicle } \\ \text { psi } & =\text { pounds per square inch } \\ \text { VCE } & =\text { Vapor Cloud Explosion } \\ \text { WSTF } & =\text { White Sands Test Facility }\end{array}$

\footnotetext{
${ }^{1}$ Senior Engineer, Bangham Enginering, 1300 Meridian St, Suite 11, Huntsville AL 35801, AIAA Senior Member.

${ }^{2}$ Engineer, Bangham Enginering, 1300 Meridian St, Suite 11, Huntsville AL 35801.

${ }^{3}$ AST, Aerospace Flight Systems, EV33, MSFC, Huntsville AL 35811.

${ }^{4}$ President, Bangham Engineering, 1300 Meridian St, Suite 11, Huntsville AL 35801, AIAA Member.
}

American Institute of Aeronautics and Astronautics 


\section{Introduction}

$I^{N}$ $\mathrm{N}$ order to assess crew survivability during an abort from an exploding rocket, the Launch Vehicle (LV) explosion environment must be accurately described. This is also true for the assessment of particularly dangerous payloads such as those containing radioactive material. The LV explosion environment can be broken down into three broad categories: blast wave, fragmentation, and thermal effects. For many years the typical approach to modeling a LV explosion has been to equate a particular percentage of the onboard propellant to high explosive and use the wellknown high explosive curves ${ }^{1}$ to predict such aspects as overpressure, impulse, and wave speed. Although this method is simple and can be useful in certain circumstances, it is known that it does not accurately capture the physics of rocket propellant explosions. For example,

but virtually all of them [LV explosions] are non-ideal. 3. TNT Equivalency is not a good criterion for evaluating non-ideal explosions and should be replaced, once our understanding improves. 4. Scaling laws for accidental explosions will be relatively easy to develop once our understanding of non-ideal explosions improves. 5. A considerable amount of work, both theoretical and experimental, is needed in this area ${ }^{2}$.

and,

The blast waves from liquid propellant explosions are highly variable, and characterized by low overpressures and high impulses near the source. These blast waves are therefore initially very different from blast waves from an equivalent weight of TNT, which should not be used to estimate blast effects closer to the source than the range corresponding to an overpressure ratio of about one or two atmospheres. The use of a TNT equivalent blast wave beyond this range may not always be a very good representation of the wave from a liquid propellant explosion, but at the present time there seems to be no practical alternative ${ }^{3}$.

This is especially true in the near field where crew and sensitive payload survivability needs to be assessed. Since high explosives are by definition point-source supersonic combustion events, they predict extremely high overpressures in the near field, whereas propellant explosions are large volumes of gaseous material that most likely combust at subsonic speeds ${ }^{4,5}$.

Therefore, as an initial step a literature review was conducted in an effort to locate data from full-scale LV explosion accidents and tests. Additionally, trips were taken to several libraries and launch sites to collect data. The goal of the data collection was to build empirical models of LV explosions so that a more accurate model could be used for survivability assessment, and to aid in developing improved analytical and numerical models. Most of the empirical data were found in declassified LV accident reports. The majority of the accident reports came from the 1960s when the LV industry had a higher rate of explosions. Currently, approximately 30 accidents were found to have applicable documented explosion data (not necessarily overpressure data) ${ }^{6-29}$. Some of this data was as simple as a report on the payload survival and some was as extensive as pressure traces, radiometric readings, and hundreds of fragment measurements. The LV explosion study was broken into three broad categories: hypergolic rockets, cryogenic rockets, and solid rocket boosters. This paper discusses results for the cryogenic rocket explosion.

Many documents were found containing data recorded from various tests used to simulate LV explosions. The test series out of NASA White Sands Test Facility (WSTF) called HOVI (Hydrogen/Oxygen Vertical Impact test) and LSHOE (Large Scale Hydrogen/Oxygen Explosion) contained much useful data ${ }^{30-33}$. The joint NASA/Air Force (AF) test series called Project $\mathrm{PYRO}^{22}$ also delivered a large amount of data. Documents from about 10 other applicable tests were found. However, most of these contained small quantities of propellant and/or uncontrolled variables, so were not as useful.

Many theoretical and experimental documents were found pertaining to the physical processes of mixing, vaporizing, and combusting cryogenic propellants. These were useful in interpreting the measured blast wave data from tests and accidents. They were also helpful in guiding the construction of our latest liquid hydrogen/oxygen explosion model. Other documents were found which describe the shock physics of combusting gases. These theoretical papers focused on the Chapman-Jouguet (C-J) model ${ }^{34-36}$ and the Zel'dovich, von Neumann, and Doering (ZND) model ${ }^{37-40}$. Several papers were found that described experiments designed to measure the combustion pressure of gaseous hydrogen and oxygen at various mixture ratios and dilutant concentrations. These were used as inputs into the new blast model. Specific works by Dr. E. A. Farber ${ }^{41-48}$ and Mr. E. J. Tomei ${ }^{49-52}$ were useful in this task.

Finally, documents were sought that described existing models for cryogenic propellant explosions. Many documents for the standard high explosive or TNT model were found. Many papers were found that described numerical models for various aspects of the vaporizing, mixing, combustion, and propagation processes. One

American Institute of Aeronautics and Astronautics 
particular model, the vapor cloud explosion (VCE) model by Baker, Tang, and Strehlow ${ }^{53-56}$ was particularly helpful in understanding the physics of gas cloud explosions and bounding the problem.

\section{History of Payload Survival}

As the literature review was conducted, it became apparent that the LV explosion environment was more survivable than the authors and many others had assumed. In fact, every payload that was in close proximity to a LV explosion for which enough data existed to assess its survivability, did indeed survive (see Table 1 and Table 2). It should be noted that the payloads listed in Table 1 survived the LV explosion, but not necessarily other events such as eventual impact with the Earth. The Space Shuttle Challenger accident is, unfortunately, a good case study. According to the joint NASA/DOE/INSRP report ${ }^{24,25}$ on STS 51L the orbiter survived the explosion but was torn into major sections by the resulting large-angle-of-attack aerodynamic loads. The crew compartment remained intact with evidence of living crew until it impacted the Atlantic Ocean. Confirmation of this scenario was confirmed by personnel involved in the Challenger recovery and investigation. This underscores the need for more accurate explosion models. If crew survivability is possible, or even likely, then designing the other life-critical hardware so that it continues to function after the explosion is extremely important. Incorrectly assuming that the crew would perish if too close to an explosion could lead to taking unnecessary avoidance risks, or leave them without proper survival capability after the explosion.

\section{Table 1 List of Payloads Confirmed to Have Survived Launch Vehicle Explosion}

\begin{tabular}{|l|c|c|c|}
\hline \multicolumn{1}{|c|}{ Launch Vehicle } & Launch Date & Payload & Reference \\
\hline Vanguard TV-3 & 6 Dec 1957 & TV-3 & $6,7,57$ \\
\hline Thor Able I 127 & 17 Aug 1958 & Pioneer 0 & 58 \\
\hline Atlas 50D & 29 Jul 1960 & Mercury Capsule & 59 \\
\hline Atlas 100D & 25 Apr 1961 & Mercury Capsule & 60 \\
\hline Atlas 17E & 17 Jun 1961 & Mark 3 Mod 1B RV & 61 \\
\hline Atlas 32E & 10 Nov 1961 & RVX-2A, No. 424A & 62 \\
\hline Atlas 11F & 9 Apr 1962 & Mark 4 Mod 1B RV & $7,13,63$ \\
\hline Apollo A-003 & 19 May 1965 & Boilerplate 22 & 64,65 \\
\hline STS 51-L & 28 Jan 1986 & Challenger & 24,25 \\
\hline Delta II 7925 & 17 Jan 1997 & GPS IIR & 66,67 \\
\hline
\end{tabular}

Table 2 Summary of Payload Survival Study

\begin{tabular}{|l|c|c|c|}
\hline \multicolumn{1}{|c|}{ U.S. Only Full-Scale Liquid LV Explosions Studied to Date } & Pad & $\begin{array}{c}\text { In- } \\
\text { Flight }\end{array}$ & Abort \\
\hline Payload survival and nominal operation post-explosion & 2 & 6 & 2 \\
\hline Payload remains intact, but no report to confirm nominal operation & 0 & 5 & 0 \\
\hline No payload & 11 & 0 & 0 \\
\hline Payload survival unknown & 17 & 51 & 0 \\
\hline Payload destroyed by explosion & 0 & 0 & 0 \\
\hline
\end{tabular}

\section{Cryogenic Launch Vehicle Explosions}

\section{A. Empirical Data}

To date, 13 accidents 9, 10, 14, 16, 18-21, 26, 63, 69 and 2 destruct tests with full-scale flight tanks ${ }^{22}$ have been identified where overpressure data have been measured. The measured overpressures from these 15 launch vehicle explosions are shown in Figure 1. All of these accidents occurred on or near the launch pad. Therefore, there were many explosions (approximately 3 to 12) observed in each accident as the propellants mixed, exploded, re-contacted, and exploded again. Review of LV explosion films have shown that, for in-flight explosions, typically only one to three

American Institute of Aeronautics and Astronautics 
explosions occur. Since most of the pressure gauges used to measure the blast wave overpressures in these accidents were passive, the data collected are only the maximum values of the largest explosions. If active gauges had been used, then there would be a significant amount of data portrayed below the maximum overpressure data shown in Figure 1.

Due to the state-of-the-art and technical understanding at the time that the data in Figure 1 was taken, no attempt was made to distinguish the incident pressure wave from various reflections in the resulting data. But, since the blast gauges used to measure the overpressure in these accidents were close to the ground, they measured the overpressure within the Mach stem of the blast wave. This means that the actual incident overpressures from these explosions were at least a factor of 2 lower than what was measured ${ }^{70}$.

Figure 1 shows that at $100 \mathrm{ft}$.

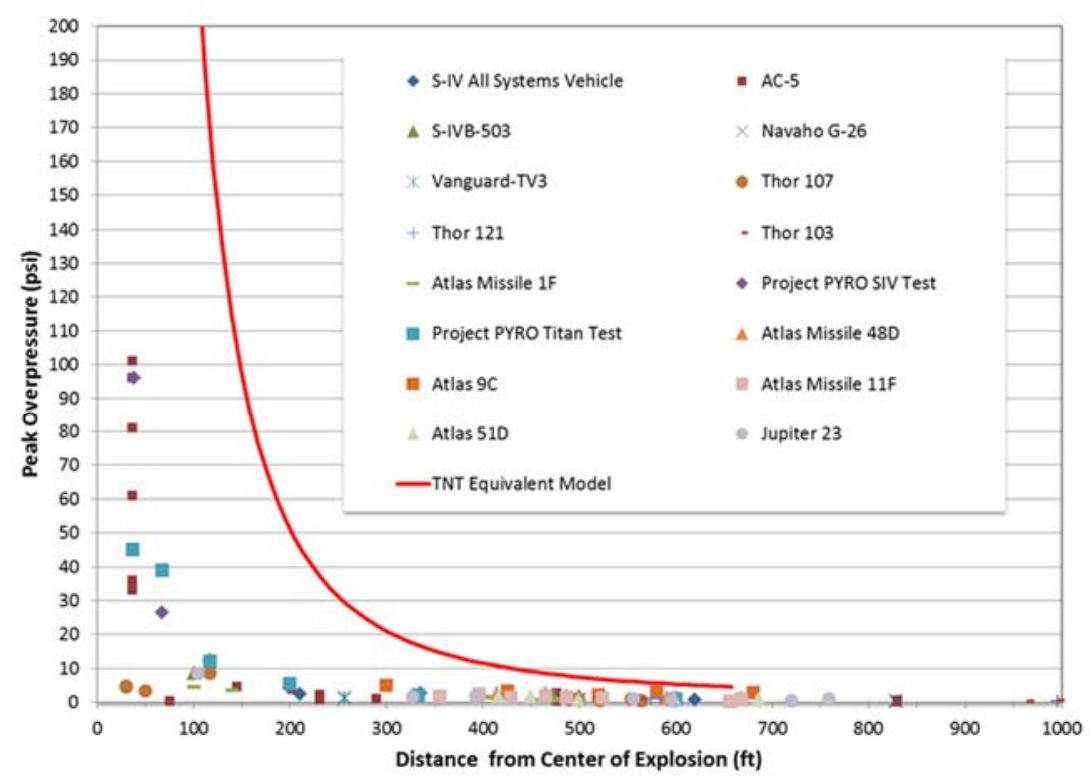

(the typical distance a crew capsule would be if the first stage exploded) the measured overpressures range from 0 to $20 \mathrm{psi}$. This means that a crew capsule would experience an incident overpressure of around 0 to $10 \mathrm{psi}$ if it was on the rocket when it exploded. The red curve in Figure 1 is a statistical TNT equivalence model used by NASA during Project Constellation to predict the explosion of the Ares I LV. As is typical of TNT models, it predicts extremely high overpressures in the near field.

One of the unresolved areas of cryogenic propellant explosions is the difference between LOX/RP and $\mathrm{LOX} / \mathrm{LH}_{2}$ explosions. It is clear that the mixing and combustion of the two are different since one fuel is cryogenic and the other is not. What is not known is whether this leads to a practical difference in the blast waves produced by these two propellant combinations. Some, such as High ${ }^{71}$, have suggested that there is not an appreciable difference by showing

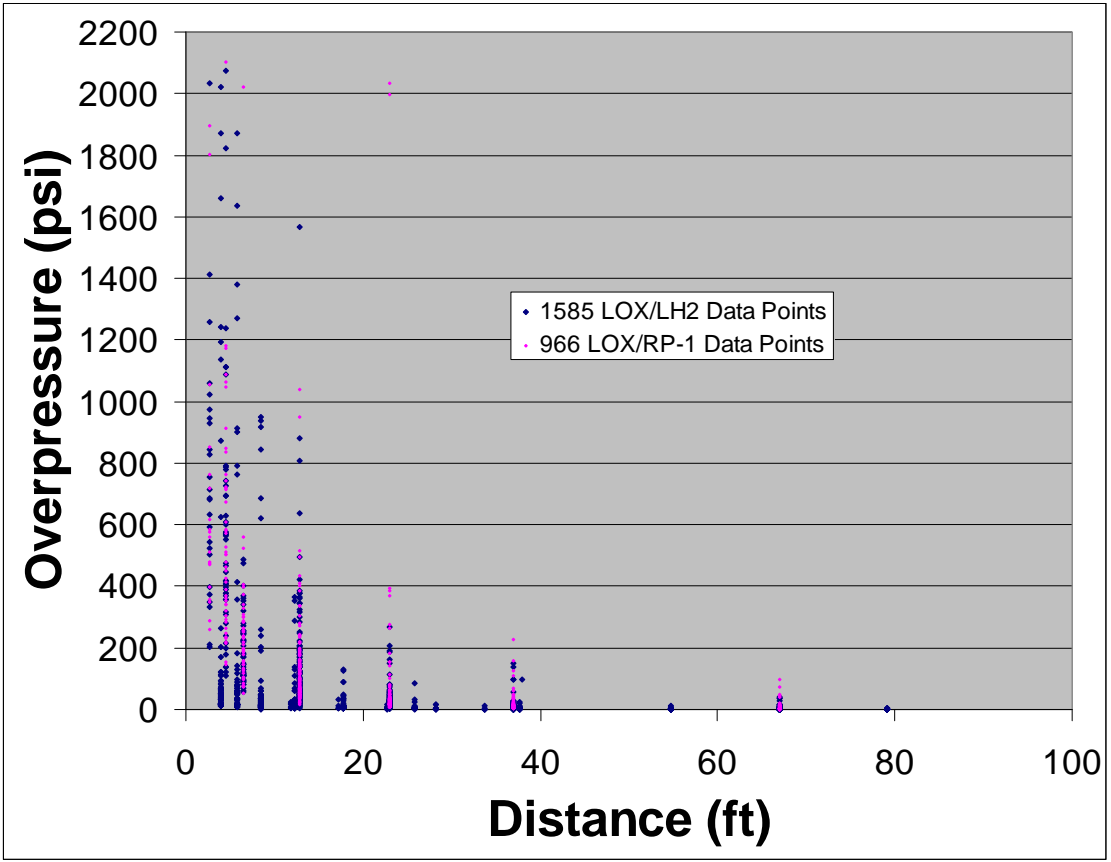

Figure 2. LOX/RP versus $\mathrm{LOX} / \mathrm{LH}_{2}$ Explosion Overpressures. experimentally that "If the ignition delays in $\mathrm{LOX} / \mathrm{LH}_{2}$ launch-vehicle failures are not generally greater than the ignition delays in LOX/RP-1 launch-vehicle failures, the $\mathrm{LOX} / \mathrm{LH}_{2}$ system should not pose a greater explosive hazard under severe failure conditions than would a LOX/RP-1 system." He also states "It is established experimentally that, 
for a given $\mathrm{A}_{\mathrm{c}}$, the explosive yield of $\mathrm{LOX} / \mathrm{LH}_{2}$ is similar to that of LOX/RP-1" ${ }^{71}$. However, others, such as Tomei ${ }^{49-52}$, have shown a difference between LOX/RP and $\mathrm{LOX} / \mathrm{LH}_{2}$ explosions.

To examine this issue, all the accident and test overpressure data using LOX/RP and LOX/LH $\mathrm{LH}_{2}$ propellants of at least $200 \mathrm{lbs}$ were studied (see Figure 2). Approximately 2,500 data points (of which almost all were uncorrected for height of burst effects) were used from a few hundred tests and accidents. With a 95-percent confidence level, no difference between the peak overpressure of two propellant types could be shown. Therefore, a practical difference between the large-scale explosions of the two propellants has not yet been found.

As a singular point comparison, two tests from project PYRO ${ }^{22}$ are shown in Figure 3. The Titan 1 first stage was filled with 94,000 lbs of LOX/RP, and the bulkheads between the two tanks was catastrophically ruptured. The Saturn S-IV was filled with a similar weight of $\mathrm{LOX} / \mathrm{LH}_{2}$ propellant. Its common bulkhead was also catastrophically failed. The overpressures in Figure 3 from these two different propellants can be seen to follow a similar trend.

Peak overpressure is insufficient to fully analyze the effect of a blast wave on a structure. Impulse, or the area under the pressure-time curve, is also critical for determining the effect of a blast wave on a solid structure like a crew capsule. The correlation between peak overpressure and impulse from high-explosive (TNT) blast waves is well characterized. However, this correlation for cryogenic propellant explosions is not fully established. In general, propellant explosions can have significantly higher impulses than a TNT blast wave of the same overpressure because they can have a higher energy density than high explosives. However, it remains to be proven how efficient this energy is transferred into the blast wave. The fact that cryogenic propellant explosions typically decay more slowly than standard TNT explosions of the same overpressure is evidence of higher impulse.

Figure 4 shows the measured impulse from two full-scale test explosions ${ }^{22}$ and the measured impulse from four different explosions ${ }^{18,26,69}$ that occurred during an Atlas-Centaur pad explosion. As is typical with most blast parameters, the test data are generally more extreme than the actual accident data. Presumably this is because tests are designed to maximize the explosive effect while accidents have many random variables that make ideal blast conditions almost impossible to achieve. Although the data in Figure 4 are limited, it is the only known measured impulse from full-scale tests or accidents. It can be used for assessing capsule, building, and other range structure survivability during an explosion event, but caution should be used if such limited data are to be used in such a manner.

A $4,000-1 \mathrm{bm}$. TNT curve is also included in Figure 4 for reference. The TNT curve generally follows that of the two tests, which used approximately $90,000 \mathrm{lbs}$ of $\mathrm{LOX} / \mathrm{RP}$ or LOX/LH2. It significantly overpredicts the accident data that came from approximately $300,000 \mathrm{lbs}$ of $\mathrm{LOX} / \mathrm{RP} / \mathrm{LH} 2$. This illustrates the complexity of trying to fit propellant explosions to high-explosive data and, even more so, fitting accident propellant explosions to high-explosive data. Additionally, this approach is further confounded when a second parameter, like overpressure, is used to fit to

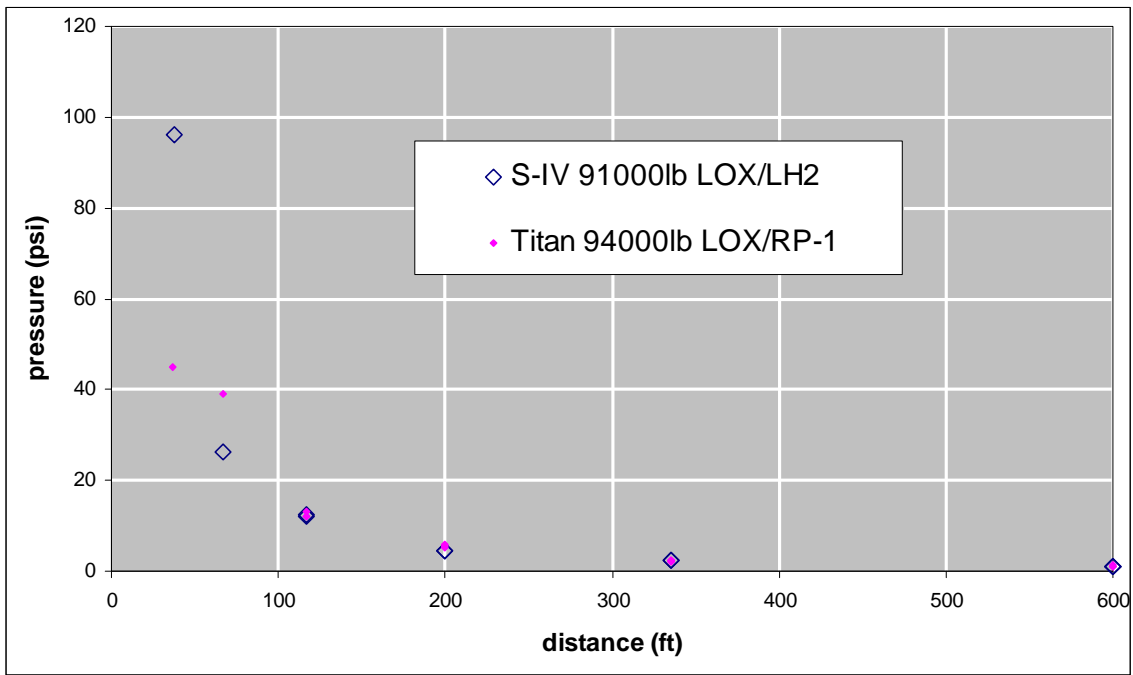

Figure 3. Titan I versus Saturn S-IV Common Bulkhead Failure Explosion Overpressures. high-explosive data since the overpressure and impulse from the same propellant explosion generally give two different TNT equivalencies. 
Another key parameter to understanding the LV explosion environment is the blast wave speed, or the speed at which the shock wave travels through the atmosphere. This parameter is important for two reasons. First, it is a physical indicator of the blast physics. If the blast wave is supersonic, then a detonation is occurring and the physics of detonation should be used to model the explosion. If the blast wave is moving at the speed of sound, then the explosion has either decayed to a weak shock or was only a deflagration initially, not a detonation. The second reason blast wave speed is important is for practically

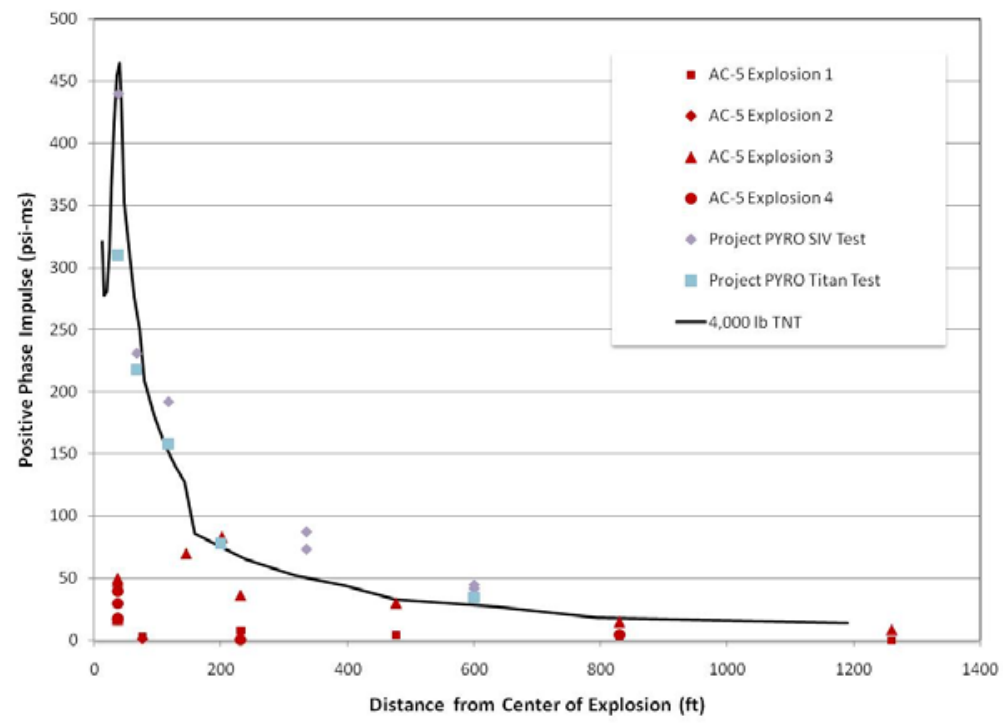
assessing crew survivability. The speed at which the blast wave travels is part of what determines how much warning time an escaping capsule will need to get the capsule to a safe distance. Also, if the blast wave is a sonic event, then once the launch vehicle is travelling faster than the local speed of sound in its trajectory the blast wave will be unable to transmit through the shock layer and catch up with an escaping crew capsule.

Figure 5 shows the measured wave speed data from five different explosions ${ }^{18,} 26,68,69$. Four of those explosions came from the Atlas-Centaur pad explosion. The green line in Figure 5 is the speed of sound in air at standard temperature. It can be seen that the measured wave speeds beyond about $500 \mathrm{ft}$. are close to a Mach 1 (or acoustic) wave. Speeds closer than $500 \mathrm{ft}$. are shown to be faster than Mach 1 at standard temperature. Since this is the region where the fireball and heated air exist, it is impossible to determine whether the wave speed in this region is supersonic or simply sonic at a higher temperature. In general, however, the measured blast wave speeds do not show conclusive evidence of a detonation and hint at a purely sonic event.

\section{B. Cryogenic Propellant Explosion Model}

A fireball and overpressure model was developed to identify threats to the crew capsule from the overpressure associated with the shockwave generated in a worst-case detonation of a stoichiometric mixture of $\mathrm{LV}$ oxidizer and fuel. Research was done to determine the maximum overpressure possible in the event of a detonation of a stoichiometric mixture of oxygen and hydrogen at $100 \mathrm{~K}$. The maximum theoretical overpressure was found to be approximately $480 \mathrm{psi}^{36}$ for hydrogen and oxygen. Experimental values found (Table 3) support the findings. It is believed that a 480-psi overpressure would be unlikely

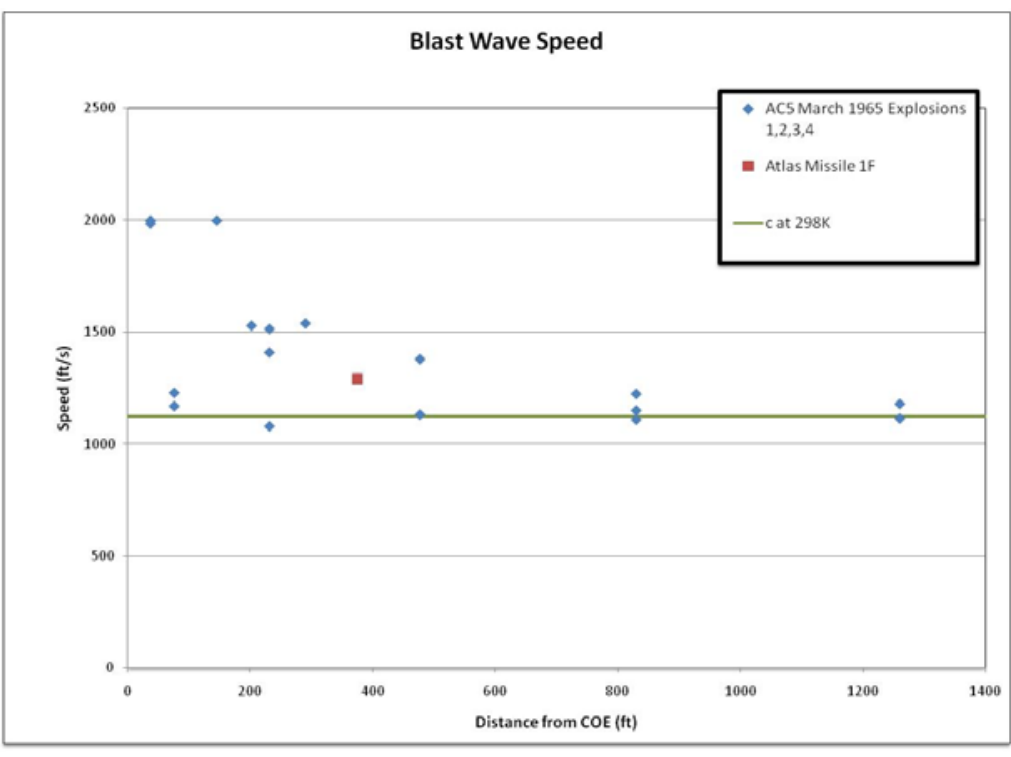
in a pad environment; further work is being done to evaluate this theory. 
Table 3. Experimental Hydrogen Detonation Pressures.

\begin{tabular}{|c|c|}
\hline \multicolumn{2}{|c|}{ Hydrogen/Oxygen Detonation Pressure } \\
\hline Author & Pressure (psi) \\
\hline Edwards $^{36}$ & 397 \\
\hline Hansen $^{72}$ & 305 \\
\hline Hord $^{73}$ & 294 \\
\hline Zabetakis $^{74}$ & 279 \\
\hline Hydrogen/Air Detonation Pressure $^{74}$ & 156 \\
\hline Kang $^{75}$ & 181 \\
\hline Kinney $^{76}$ & 225 \\
\hline Van Wingerden $^{77}$ & 189 \\
\hline Zeldovich $^{37}$ & \\
\hline
\end{tabular}

The maximum overpressure is associated with a true detonation, a supersonic propagation of the combustion wave in the flammable medium. A deflagration would produce a much lower overpressure, and, as can be seen in Table 3 , combustion with air would reduce the maximum overpressure even more. These facts can be taken into account from a probabilistic standpoint when modeling accidental LV explosions. Also, the initiator plays an important role in the type of combustion produced. Usually a detonation can only be produced through the use of a high explosive, a source that sends a supersonic wave through the medium. In general, a deflagration will be initiated when the ignition is a low-energy source such as an open flame or an electrical short. Experimental results from a setup in which identical mixtures of hydrogen and air were initiated by either $0.1 \mathrm{~kg}$ of C-4 or an electronic spark indicated an order of magnitude difference in the resulting overpressure ${ }^{78}$. The conditions for a true detonation are unlikely in an LV accident. Few detonation sources exist on an LV, typically just the frangible nuts and the destruct system. However, many low-energy ignition sources will be present in the event of an LV accident-particularly the auto-ignition phenomenon discussed below - making a lower overpressure deflagration significantly more likely, as indeed the data shows (see overpressures in Figure 6).

Research performed by Dr. Eric Farber and Wallace Boggs $41-48,79$ indicates that a finite amount of liquid fuel and oxidizer can be mixed before auto-ignition occurs, known as the Farber limit. Their work "confirmed that autoignition occurs and prevents the mixing of more than the 'critical mass' and therefore limits the explosive yield to several thousand pounds..." In the case of $\mathrm{LOX} / \mathrm{LH}_{2}$, the Farber limit is approximately $2,300 \mathrm{lbm}$. For our cryogenic propellant explosion model, the Farber limit mass was assumed to be a stoichiometric sphere (or hemisphere if on the ground) of gases at $100 \mathrm{~K}$ at ignition, an approximately 38 -ft. diameter sphere (or 50 -ft. hemisphere). The ignition source was assumed to be adequate to cause a detonation as opposed to a deflagration. These assumptions defined the size of the fast initial fireball and the maximum possible overpressure

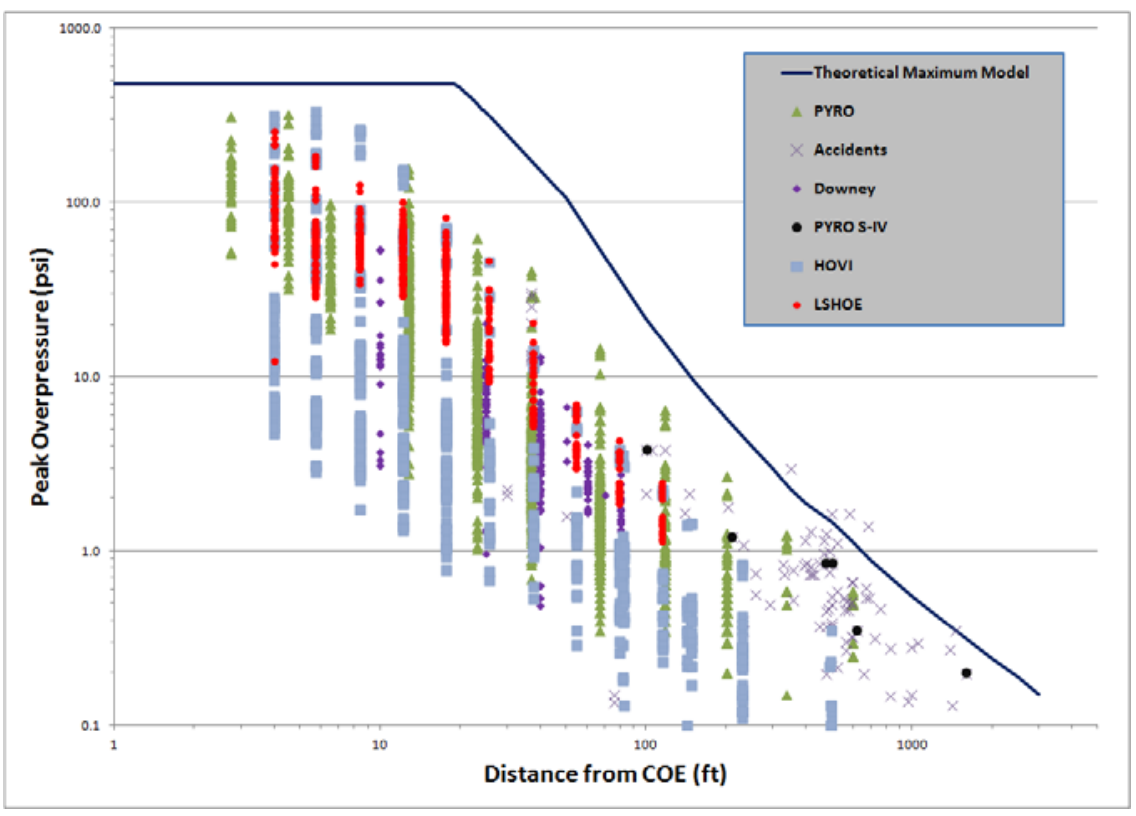

Figure 6. Explosion Model versus All Known Accident and Test Data. within the fireball.

American Institute of Aeronautics and Astronautics 
Research into the maximum overpressure for a stoichiometric mixture of gases classified two stages of fireball. The "primary fireball" is driven by the coupled shock and combustion process. The duration of the primary fireball is a few milliseconds and is only visible as a rapidly expanding luminous boundary on high-speed video. It is strongly associated with the maximum pressure and temperature gradients in the event. The pressure wave (shock) and the flame front are coupled and are approximately together in the primary fireball. The maximum overpressure possible in the primary fireball is approximately $480 \mathrm{psi}$, and the maximum diameter is around 40 feet $\left(\mathrm{LOX}^{\mathrm{L}} / \mathrm{LH}_{2}\right)$. The transition from primary to secondary fireball is defined as the time when the pressure wave becomes uncoupled from the flame front and begins to decay. The secondary fireball is the structure typically associated with the accident as it is easily visible to the naked eye. No significant pressure wave is associated with the secondary fireball since the pressure wave has expanded well outside the flame front.

Our cryogenic propellant blast overpressure model for hydrogen and oxygen propellants was developed using the Farber limit of 2,300 lbs at a stoichiometric ratio. The propellants were assumed to be gaseous at $100 \mathrm{~K}$ and collected in a sphere (or hemisphere if on the ground) whose radius was calculated from the ideal gas law. The sphere of gas is the only volume in which the primary fireball can occur. In the event of an explosion, the maximum theoretical overpressure can occur anywhere within the sphere; therefore, it was assumed that the maximum pressure occurs everywhere within the sphere to be wholly conservative. This maximum overpressure was held constant to the edge of the sphere and then decayed out to 3,000 ft from the center of explosion. The decay overpressures versus distance were determined using the Baker curves ${ }^{70}$, which are empirical curves for bursting spherical gas vessels. The result is shown below in Figure 6. The data points in Figure 6 represent experimental and accident data collected over the duration of this task from various documents, covering a time period from 1957 to 2008. As the understanding of blast and shockwave interactions progressed, the data collection and analysis methods also evolved. This is particularly evident in the differences in analysis between the PYRO experiments from the 1960s and the HOVI and LSHOE experiments from the 1990s. The raw data collected in the PYRO and HOVI experiments is of similar magnitude, but the HOVI data are corrected for Height of Burst (HOB) effects and are subsequently more reliable and accurate.

Other researchers have developed explosion models that also have a constant pressure initial region and a decaying pressure secondary region. For example, the pioneering work by Baker, Tang, and Strehlow ${ }^{53-56}$ has led to a commonly used model in the chemical industry called the Vapor Cloud Explosion (VCE) model. Also, empirical work conducted by John W. Taylor in conjunction with NASA White Sands Test Facility has a similar two-region structure $^{79}$.

\section{Statistical Application of Physical Model}

To identify overpressures which are more realistic, a basic statistical analysis was performed on the free stream* overpressure data from Project HOVI and Project PYRO. These two experimental programs are the only available cryogenic explosion data between the 500 and $91000 \mathrm{lb}$. range which possess blast sensors within the combustion zone. Furthermore, HOVI is unique in that it possesses reported data of both pressure sensors and high speed camera data within the combustion zone. Figure $7{ }^{5}$ shows a graph of the growth rate of the luminous boundary over time for HOVI 14 , the fast initial fireball was taken to end at $40 \mathrm{~ms}$ or $12 \mathrm{~m}$ diameter where there is a distinct change in slope of the luminous boundary.

This unique HOVI data was used to identify patterns in the response of sensors within the reported combustion zone in order to identify similar patterns within the PYRO data. This pattern was identified as a region of approximately constant pressure in a range of up to $23 \mathrm{ft}$. from the assumed center of explosion. The average overpressure for these explosions is $\approx 60 \mathrm{psi}$ with a 2 -sigma bound of $\approx 190 \mathrm{psi}$. Interestingly, this analysis also identified that the maximum overpressure was largely a

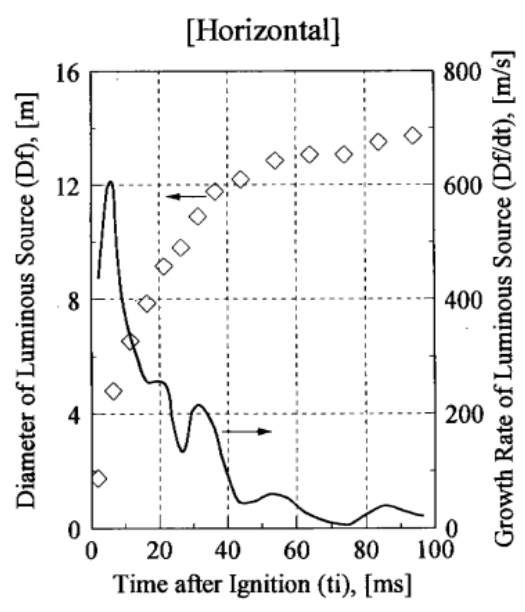

\section{Figure 7. Growth Rate of a Typical Cryogenic Propellant Explosion 5.}

\footnotetext{
${ }^{*}$ Unless perfectly designed and positioned, blast pressure gauges will cause a local increase in the blast pressure where it is measured. This was not widely known until after this phenomenon (sometimes called of Height of Burst) was declassified from the nuclear weapon industry. Nowadays, most experimenters position the sensors and then "correct" or post-process the data after the center location of the explosion has been found by high speed camera analysis. The HOVI test program did this for all the measured data and labeled it "free stream" in each set of tabular data. Project PYRO did not conduct this process.
} 
function of mixing time and less a function of propellant mass. This statistical HOVI data was used generate the mean (green line) and 95\% (red line) in Figure 8. It should be noted that the statistical models are still physical models, not merely curve fits to the shown data. Also, the PYRO and accident data is not corrected for HOB effects and is therefore elevated above incident overpressure.

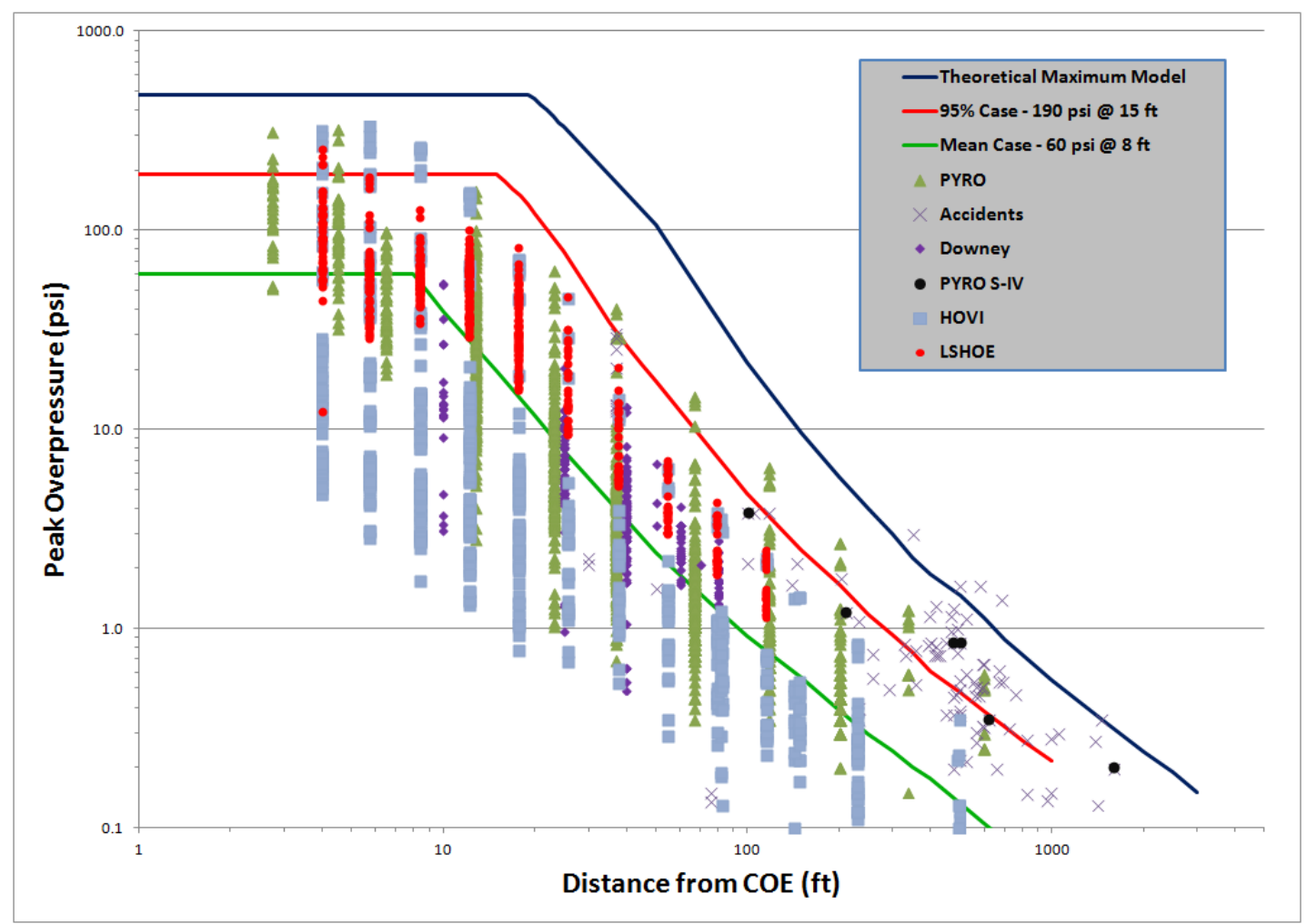

Figure 8. Statistical Cryogenic Propellant Explosion Model versus All Known Accident and Test Data.

\section{Additional Studies}

Accident and test data for solid rocket explosions was collected in conjunction with the cryogenic rocket explosion data. This led to a separate physical model for SRB explosions with an abstract accepted at the Joint Army Navy NASA Air Force (JANNAF) December 2014 conference. Additionally, a significant amount of fragmentation data such as size, mass, and impact location have been collected for both cryogenic and solid rockets. This has led to the generation of semi-empirical LV fragmentation models, which, when coupled with the appropriate blast model, has been used to accelerate each individual fragment and propagate them until they hit the ground for a variety of LVs and failure scenarios. This allows for crew and range survivability studies to be conducted. Finally, data on the size, temperature, and duration of the fireballs produced from the accidental explosions was also collected. This thermal data was used to make simple thermal models which can be used to assess the survivability of heat-sensitive material, like escape capsule parachutes. All empirical data collected in this endeavor, along with originating reports, resides in a digital database at NASA and Bangham Engineering, Inc. located in Huntsville, AL.

As this data was collected and models developed, it became apparent that there was key empirical data missing in order to be able to fully characterize all aspects of the launch vehicle explosion environment. For instance, all tests and accidents only collected fragment data down to an arbitrary minimum size/mass.

Therefore, a few test programs have been initiated to fill the gaps in the data and physical models. First, two cannons with 6 inch and 14 inch bores have been constructed for the purpose of better understanding how LV tank fragments are formed and if large numbers (on the order of 10,000 pieces) of small fragments are produced. These two-stage cannons produce a representative blast wave that is then allowed to impact a section of LV tank structure. The fragmentation is viewed with high speed cameras and post-test analysis is conducted on each fragment. Second, an unconfined gaseous combustion system has been built to allow for various propellants to be mixed in a variety of concentrations with air or pure oxygen, and then ignited. The ensuing overpressure is measured with blast gauges and the flame speed is calculated from high speed camera data. The combustible gas and blast gauges are both high enough

American Institute of Aeronautics and Astronautics 
off the ground that only incident overpressure is measured without any height-of-bust effects. Data from these tests are being used to improve current blast and fragment models.

\section{Conclusion}

As new launch vehicles and launch pads are built, a better understanding of the launch vehicle explosion environment can save lives and reduce costs. To that end, an empirical-based model of cryogenic launch vehicle explosions has been developed. Blast overpressure predictions from this model agree well with all known full-scale launch vehicle accident and test explosions. These new blast predictions are less extreme than have been typically predicted by other models such as TNT equivalency. Indeed, the lower blast overpressure predictions seem to agree with historical payload survival rates. This new model can be used for assessing crew and critical hardware survival in the event of a catastrophic explosion. It can also be used in the design and operation of launch vehicle systems to improve survivability.

\section{Acknowledgments}

Efforts for this task were funded by the NASA Marshall Space Flight Center and the NASA Engineering and Safety Center.

\section{References}

${ }^{1}$ Kingery, C. N., Bulmash, G., “Airblast Parameters from TNT Spherical Air Burst and Hemispherical Surface Burst,” ARBRLTR-02555, April 1984.

${ }^{2}$ Strehlow, R. A., Baker, W., E., “The Characterization and Evaluation of Accidental Explosions,” NASA CR 134779, June 1975.

${ }^{3}$ Eck, M., and Hancock, S., "Propellant Explosion Test Data CD-ROM, Foils Engineering," July 2002.

${ }^{4}$ Bunker, R., Starritt, L., Flint, Q., Eck, M., Taylor, J., Namikawa, T., Takeno, K., "NASA/NASDA Joint Hydrogen/Oxygen Vertical Impact (HOVI) Test Program,” NASA TR-820-001R, April 2, 1998.

${ }^{5}$ Bunker, R., Eck, M., Taylor, J. W., Hancock, S., “Correlation of Liquid Propellants NASA Headquarters RTOP,” WSTF-TR0985-001-01-02, Jan 2003.

${ }^{6}$ Smalley, W. E., Anderson, D. E., “The Explosive Potential of Liquid Oxygen and RP-1 Missiles,” GM-TR-59-0000-00579, 30 January 1959.

${ }^{7}$ Thilges, J. H., "Data from Missile Post-Ignition Aborts," STLFD 66-478, 1 April 1966.

${ }^{8}$ Thompson, E. M., Report of Missile Mishap Discoverer X DRAFT," Air Force Ballistic Missile Division, 29 February 1960.

${ }^{9}$ Maloy, T. L., "Missile 9C Failure, 24 September 1959," Convair General Dynamics Corporation, FTA 6182, 1 October 1959.

${ }^{10}$ Fletcher, R. F., "Characteristics of Liquid Propellant Explosions," Annals of New York Academy of Science, 152, I, 1968, pp. 432-440.

${ }^{11}$ General Dynamics/Astronautics, "Missile 1F Investigation Report, Run S1-613-14-01,” AC-62-0031, July 1962.

${ }^{12}$ General Dynamics/Astronautics, "WS 107A-1 Flight Test Working Group Flight Test Report Atlas Missile 32E," November 1961.

${ }^{13}$ Berman, S. D., Green, J., Flanders, C. W., Bradley, D. M., Baird, G. G., King, K. M., "Hardware Investigation Report, SM 65F Missile Test Accident, Atlas 11F, AFSN 605534,” STL-6101-7576-RC-000, 11 July 1962.

${ }^{14}$ Withee, W. W., Rosenbaum, M., "Flight Test Evaluation Report Missile 48D,” AZC-27-120, 28 April 1960.

15"Launch Hazards Assessment Program Report on Test 205 from Pad Abort Measuring System (PAMS)," 7240-65-32, 10 May 1965.

16“Denfense Explosives Safety Mishap Analysis Module (ESMAM) Specific Mishap Detail," 1159.00, 2 March 1965.

${ }^{17}$ Cocchiaro, J., "Fire and Explosive Hazards of Liquid Propellants CPIA Technology Review," CPIA Bulletin, Volume 24, Number 1, January 1998.

${ }^{18}$ Perlman, S. S., "Investigation of the Atlas-Centaur Vehicle Explosion," John F. Kennedy Space Center Safety Division Report, 2 March 1965.

${ }^{19}$ Gayle, J. B., "Investigation of S-IV All Systems Vehicle Explosion,” NASA TN D-563, September 1964.

${ }^{20}$ Gayle, J. B., "Liquid Propellant Blast Hazards," CPIA Pub 56, August 1964.

${ }^{21}$ Debus, K. H., "Report of Investigation S-IVB-503 Incident January 20, 1967," George C. Marshall Space Flight Center, 8 February 1962.

${ }^{22}$ Willougby, A. B., Wilton, C., Mansfield, J., "Liquid Propellant Explosive Hazards Final Report Volume 2 - Test Data," AFRPL-TR-68-92, December 1968.

${ }^{23}$ Baker, W. E., Parr, V, B., Bessey, R. L., Cox, P. A., “Assembly and Analysis of Fragmentation Data for Liquid Propellant Vessels," Minutes of the 15 $5^{\text {th }}$ Explosives Safety Seminar, Volume II, September 1973.

${ }^{24}$ Reynolds, J. R., "Final Report of the NASA/DOE/INSRP STS 51-L and Titan 34D-9 Explosion Working Group," Volume I, 16 June 1989.

American Institute of Aeronautics and Astronautics 
${ }^{25}$ Reynolds, J. R., "Final Report of the NASA/DOE/INSRP STS 51-L and Titan 34D-9 Explosion Working Group," Volume II, 17 June 1989.

${ }^{26}$ Kite, F. D., Webb, D. M., Bader, B. E., Golub, C. N., "Launch Hazards Assessment Program, Report on Atlas/Centaur Abort," Sandia Laboratory and Pan American World Airways, PAFB, SC-RR-65-333, October 1965.

${ }^{27}$ White, Jr., T. H., “Abortive Missile Report Test 205,” 1965.

${ }^{28}$ Miller, W. F., Withee, W. W., "Flight Test Evaluation Report Missile 27E," Division Report No. AE61-0548.

${ }^{29}$ Gayle, J. B., Bransford, J. W., "Size and Duration of Fireballs from Propellant Explosions," NASA TM X-53314.

${ }^{30}$ Bunker, R., Dees, J., Eck, M., Weaver, R., "Propellant Reaction Characterization Studies (LH2/N2O4)," NASA WSTF \#9428722, November 18, 1994.

${ }^{31}$ Bunker, R., Dees, J. Eck, M., Weaver, R., Benz, F., "Large-Scale Hydrogen/Oxygen Explosion Project Special Interim Test Data Report,” NASA WSTF \# 95-28791, January 5, 1995.

${ }^{32}$ Bunker, R., Starritt, L., Flint, Q., Eck, M., Taylor, J., Namikawa, T., Takeno, K., "NASA/NASDA Joint Hydrogen/Oxygen Vertical Impact (HOVI) Test Program,” NASA TR-820-001R, April 2, 1998.

${ }^{33}$ Bunker, R., Eck, M., Taylor, J. W., and Hancock, S., "Correlation of Liquid Propellants NASA Headquarters RTOP," WSTFTR-0985-001-01-02, Jan 2003.

${ }^{34}$ Turns, S. R., An Introduction to Combustion: Concepts and Applications, $3^{\text {rd }}$ edition, New York, McGraw-Hill Publishing, 2012.

${ }^{35}$ Glassman, I., Yetter, R., Combustion, $4^{\text {th }}$ edition, Academic Press, 2008.

${ }^{36}$ Edwards, D. H., Williams, G. T., Breeze, J. C., "Pressure and Velocity Measurements on Detonation Waves in HydrogenOxygen Mixtures," Journal of Fluid Mechanics, 6, pp. 497-517, 1959.

${ }^{37} Z$ el'dovich, Y. B., "On the Theory of the Propagation of Detonation in Gaseous Systems," National Advisory Committee for Aeronautics, Technical Memorandum 1261, November 1950.

${ }^{38}$ Sharp, D. H., Simmons, L. M., Introduction to Detonation Theory, Wildon Fikett University of California Press, Long, England, 1985.

${ }^{39}$ Mahmoudi, Y., Mazaheri, K., "Triple Point Collision and Hot Spot in Detonations with Regular Structure," Italian Section of the Combustion Institute, 11-15 September 2011.

${ }^{40}$ Swift, D. C. and White, S. J., "An Evaluation of Detonation Models," Journal De Physique IV, Volume 5, May 1995.

${ }^{41}$ Farber E. A., A Mathematical Model for Defining Explosive Yield and Mixing Probabilities of Liquid Propellants, Third Space Congress, March 1966.

${ }^{42}$ Farber E. A., "Characteristics of Liquid Rocket Propellant Explosion Phenomena," University of Florida, November 1969.

${ }^{43}$ Farber E. A., Clement, F. W., Bonzon, C. F., "Prediction of Explosive Yield and Other Characteristics of Liquid Propellant Rocket Explosions," University of Florida, October 1968.

${ }^{44}$ Farber E. A., Deese, J. H., "A Systematic Approach for the Analytical Analysis and Prediction of the Yield from Liquid Propellant Explosions," pp. 520-531, Date Unknown.

${ }^{45}$ Farber E. A., San Martin, R. L., "Studies and Analyses of the Mixing Phenomena Liquid Propellants Leading to Yield-Time Function Relationship," Annals of New York Academy of Science, pp. 666-684, 1966.

${ }^{46}$ Farber E. A., Smith, J. H., Watts, E. H., "Electrostatic Charge Generation and Auto-Ignition Results of Liquid Rocket Propellant Experiments," October 1972.

${ }^{47}$ Farber E. A., Smith, J. H., Watts, E. H., "Prediction of Explosive Yield and Other Characteristics of Liquid Rocket Propellant Explosions Final Report," University of Florida, 30 June 1973.

${ }^{48}$ Farber, E. A. "Explosive Yield Limiting Self-Ignition Phenomena in LO2/LH2 and LO2/RP-1 Mixtures," Paper presented at the Fifteenth Explosives Safety Seminar, San Francisco, CA, pp. 1287-1303 (September 18-20, 1973).

${ }^{49}$ Tomei, E. J., "Explosive Equivalence of Cryogenic Propellants," Aerospace Corporation, 25 June 1997.

${ }^{50}$ Tomei, E. J., "Equivalence of Cryogenic Propellants," CPIA Pub 674, Vol 1, April 1998.

${ }^{51}$ Tomei, E. J., "Propellant Explosive Hazards Study," Vols I-III, The Aerospace Company, TOR-0089(4025-04)-1, October 1989.

${ }^{52}$ Tomei, E. J., "Updating the Explosive Effects of Liquid Propellants," Aerospace Corporation, Aug 1998.

${ }^{53}$ Strehlow, R. A., "Unconfined Vapor-cloud Explosions - An Overview," $14^{\text {th }}$ International Symposium on Combustion, Vol. 14, Issue 1, pp. 1189-1200, 1973.

${ }^{54}$ Tang, M. J., Baker, Q. A., “A New Set of Blast Curves from Vapor Cloud Explosions," Process Safety Progress, Vol. 18, No. 3, 1999.

${ }^{55}$ Baker, Q. A., Tang, M. J., Scheier, E. A., Silva, G. J., "Vapor Cloud Explosion Analysis," Process Safety Progress, Vol. 15, No. 2, 1996.

${ }^{56}$ Pierorazio, A. J., Thomas, J. K., Baker, Q. A., Ketchum D. E., "An Update to the Baker-Strehlow-Tang Vapor Cloud Explosion Prediction Methodology Flame Speed Table,” Wiley Interscience, DOI 10.1002/prs. 10048, 4 January 2005.

57"National Affairs: The Death of TV-3," Time Magazine, 16 Dec 1957.

${ }^{58}$ Siddiqi, A. A., "Deep Space Chronicle A Chronology of Deep Space and Planetary Probes 1958-2000," NASA SP-20024524, June 2002.

${ }^{59}$ Swenson, Jr, Loyd S., Grimwood, James M., Alexander, Charles C., “This New Ocean: A History of Project Mercury,” NASA SP-4201, URL: http://history.nasa.gov/SP-4201/ch9-3.htm, 1989.

60“Missile Failure Atlas Explodes Capsule Intact,” Universal-International News, 1961.

American Institute of Aeronautics and Astronautics 
${ }^{61}$ Thatcher, E. V., Newton, K. E., Gritton, E. W., Read, W. A., Caldwell, W. H., Henriksen, O. M., Bailey, Jr., C. W., Wignall, P. R., "WS 107A-1 Flight Test Working Group Flight Test Report Atlas Missile 17E 22 June 1961," General Dynamics/Astronautics, 27 July 1961.

${ }^{62}$ Thatcher, E. V., Newton, K. E., Solid, L. D., Swing, M. J., Caldwell, W. H., Henriken, O. M., Bailey, C. W., Davidson, T. F., Wignall, P. R., "WS 107A-1 Flight Test Working Group Flight Test Report Atlas Missile 32E," General Dynamics/Astronautics, Nov 1961.

${ }^{63}$ Thatcher, E. V., O’Malley, T. J., Henriksen, O. M., Davidon, T. P., Solid, L. D., Swing, M. J., Caldwell, W. H., Adkins, F. W., Carden, J. R., Wignall, P. R., WS 107A-1 Flight Test Working Group Flight Test Report Atlas Missile 11F," General Dynamics/Astronautics, AD852659, 30 April 1962.

${ }^{64}$ NAA/SID Apollo Engineering, "Project Apollo Flight-Test Report Boilerplate 22," North American Aviation, SID 63-14166, August 1965.

${ }^{65}$ Shea, J. A., "Postlaunch Report for Apollo Mission A-003,” NASA MSC, MSC-A-R-65-2, 28 June 1965.

${ }^{66}$ Weaver, J. R., Ward, Jr., J. A., "Delta II Fragmentation Model Final Report,” RTI/6762/06-12F, 30 September 1998.

${ }^{67}$ Deal, D. W., "Investigation of USAF Launch Vehicle Delta II-GPS IIR-1," Cape Canaveral Air Station, 17 January 1997.

${ }^{68}$ Simpson, S. R., "Missile 1F Investigation Report Run S1-613-14-01," General Dynamics/Astronautics, AC-62-0031, July 1962.

${ }^{69}$ Cocchiaro, J., Fire and Explosive Hazards of Liquid Propellants and Related Materials - An Accident Overview, CPIA Pub 661, 1 October 1997.

${ }^{70}$ Baker, W. E., Kulesz, J. J., Ricker, R. E., Bessey, R. L., Westine, P. S., Parr, V. B., Oldham, G. A., "Workbook for Predicting Pressure Wave and Fragment Effects of Exploding Propellant Tanks and Gas Storage Vessels," NASA Contract NAS3-19231, September 1977.

${ }^{71}$ High, R. W., "Some Liquid Oxygen/Liquid Hydrogen Explosive Effects in Controlled Failure-Mode Tests," NASA TN D5382, September 1969.

${ }^{72}$ Hansen, O. R., Rernoult, J., Sherman, M. P., Tieszen, S. R., "Validation of FLACS-HYDROGEN CFD Consequence Prediction Model Against Large Scale $\mathrm{H}_{2}$ Explosion Experiments in the Flame Facility," Presented at the International Conference on Hydrogen Safety, Pisa, 8-10 September 2005.

${ }^{73}$ Hord, J., "Explosion Criteria for Liquid Hydrogen Test Facilities,” National Bureau of Standards Report 10-734, February 1972.

${ }^{74}$ Zabetakis, M. G., Burgess, D. S., "Flammability Characteristics of Combustible Gases and Vapors," Bulletin 627, Bureau of Mines, U.S.G.P.O., Washington, 1965.

${ }^{75}$ Kang, H. S., Kim, S. B., Kim, M. H., No, H. C., “CFD Analysis of a Hydrogen Explosion Test with High Ignition Energy in Open Space."

${ }^{76}$ Kinney, G. F., Sewell, R. G. S., Graham, K. J., "Peak Overpressures for Internal Blast," Naval Weapons Center, 1979.

${ }^{77}$ Van Wingerden, K., Bjerketvedt, D., Bakke, J. R., "Detonations in Pipes and in the Open," Proceedings of the Petro-Chemical Congress, June 23-24, 1999.

${ }^{78}$ Wakabayashi, K., Mogi, T., Kim, D., Abe, T., Ishikawa, K., Kurodo, E., Matsumura, T., Nakayama, Y., Horiguchi, S., Oya, M., Fujiwara, S., "A Field Explosion Test of Hydrogen-Air Mixtures," First International Conference on Hydrogen Safety, Pisa, Italy. 2005.

${ }^{79}$ Boggs, W. H., "Autoignition - A Liquid Propellant Explosive Potential Limiting Phenomena," Proceedings of the Thirteenth Space Congress, Cocoa Beach, FL, 1976, pp. 4-33-4-41.

American Institute of Aeronautics and Astronautics 